cal ground. (2) The frequent lack of sufficient psychological evidence for his categories, e.g., adhesion. (3) The synthetic character of the work, in attempting to combine historical, positivistic, and idealistic motives (p. 532). (4) The wide reading of the author: good bibliographies of even minute problems are frequent. (5) The mistakeat least from the psychological point of view - of beginning with single words rather than with the sentence. We do not believe the grammatical categories can be fully comprehended in this way.

The above account has of necessity omitted many significant features of the book. It is impossible to do justice to it in a short notice. No student of the psychology of thinking can afford to neglect it.

Princeton UnIVERSity.

W. H. Sheldon.

\title{
CHARACTER AND HANDWRITING.
}

Les révélations de l'écriture d'après un contrôle scientifique.

Alfred Binet. Paris, Alcan, igo6. Pp. viii +257 .

Under the above title is reported a series of tests by the author designed to obtain answers under controlled conditions to the four following questions: Does handwriting reveal sex, age, degree of intelligence, character?

I. To answer the first question, one hundred and eighty envelopes, eighty-nine of which had been addressed by women and ninety-one by men, were submitted $(a)$ to two professional graphologists, $(b)$ to fifteen persons ignorant of the art, with instructions that they determine the sex of the writer of the superscription. The envelopes had, for the most part, passed through the mails, a fact which insured the naturalness of the writing; but all seals, headings, etc., had been removed from them. The inference of the sex of writer from the sex of the person addressed remained as a source of error.

Results showed that sex could be determined from handwriting with an accuracy above that of chance. The percentage of correct judgments varied from 63 to 78.8 per cent.; under favorable conditions it rose to 90 per cent. The professional graphologists made the best records. Three sorts of sex-suggestion were noted: writing which reveals to all observers the sex of the writer; writing the sex-revelation of which is ambiguous; writing that exhibits the signs of the opposite sex. In citing reasons for their judgments, the graphologists appealed $(a)$ to the neatness, simplicity, firmness of the man's writing in contrast with the insignificance and incoherence of the woman's; 
(b) to such graphic details as the superelevation of ' $r$ ' and ' $s$ ' in the writing of women. The author leaves open the question whether the cause of this sex-difference be found in psycho-physiological or social conditions.

2. In the test on the revelation of age in handwriting, the envelopes used in the first test were submitted a second time. The calculation of the possible number of chance successes as well as the elimination of sources of error proved much more difficult in this than in the preceding test. The author concludes that handwriting does to a certain extent reveal age, since both expert and non-professional observers were able to give judgments superior to those of chance. As before, certain specimens gave unmistakable revelations of age; others, ambiguous indications; others, evidence of an age different from the real age.

3. In the third test, on the revelation of intelligence in handwriting, eight professionals as well as many ignorant of the art returned answers. There were numerous sources of error; uncertainty, for instance, as to the degree of intelligence of the writer. To avoid the effect of suggestion on the part of the experimenter the tests were carried on by mail. To overcome suggestions from letter-content, and at the same time accede to the graphologist's demand for a personal letter, the contents of letters used were mutilated by blotting out significant words. To eliminate the personal equation in estimation of intelligence there was utilized, on the one hand, the handwriting of men whose artistic and scientific achievements guaranteed their superior ability, of such men as Ribot, Marey, Sardou, Zola ; and, on the other hand, the handwriting of adults of moderate fortune but slight achievement. Two collections of documents were submitted. The first included the writing of four inferior and thirty-three superior intelligences; the second consisted of specimens of the writing of four men of genius and twenty-five men of mediocre intelligence. Precautions were taken that no use should be made of judgments passed on handwriting that was recognized by the subject.

From the results of the test, Binet concludes that intelligence also is revealed in penmanship, although the extent of this revelation varies with the individual. The handwriting of certain geniuses bore for every observer unmistakable evidence of superiority; that of others was judged correctly in the majority of instances; certain documents offered great difficulties in the matter of interpretation. The graphic signs of intelligence, though granted an incontestable reality, are manifestly not always found in the handwriting of a man of great intelligence. 
The author includes in his discussion analyses of the graphic signs of intelligence contributed by different graphologists. These analyses do not agree wholly; and the graphologists showed varying success in practice as well as disagreements in theory. Crépieux-Jamin, the most eminent of French graphologists, made first place in the tests, giving 91.6 per cent. of correct judgment in the intelligence tests when the documents were submitted in couples. When collections of documents were submitted his percentage of correct judgments fell to 87 . Difficulty in estimating the value of graphology arises from noting the alternate successes and failures of graphologists, but Binet's figures show that there is more truth than error in their judgments. Their graphological portraits, however, are often extremely vague, although correct so far as they go.

The author urges the need of a more precise definition and interpretation of graphological signs. Vagueness results from the fact that the graphological reading is a matter, not of science, but of intuition. It is the whole, the relation of details, that is actually significant. The successes of non-experts bear witness not only to the truth contained in graphology but also to the intuitive nature of the interpretation, although on the whole non-professional readings were less accurate than the more reasoned ones of the experts.

4. The last problem concerned the revelation of character in writing. As personal judgments on character were recognized to be of limited value, use was made of documents written by great criminals and by men whose morality the author could guarantee. An attempt was made to choose the latter from the same social class as that from which the criminals came. As before the documents used were mutilated. The graphologists were unaware that the handwriting of criminals was being submitted and, in general, the methods employed involved only a gross differentiation of specimens on the basis of character of the writer. It was found difficult to estimate the results of the test. The author's general conclusion is that the errors in reading character from writing are much greater than those found in reading intelligence. The graphologists also exhibit in the latter test greater uncertainty.

In conclusion, the author states that his interest in the investigation centered in working out a method for dealing with such phenomena. These studies constitute but a fragment of a whole that should deal with all of the external signs of intelligence as manifested in physiognomy, form and lines of hand, intonation and timbre of voice, etc. Binet emphasizes the difficulty in working out a genuine 
method of control, and closes with the declaration that, although there is something of truth in graphology, it is a science of the future.

UNIVERSITY OF W YOMING.

June E. Downey.

\section{FUNDAMENTAL PROBLEMS.}

Psychology: What is It about? Mary Whiton Calkins. Journal of Philosophy, Psychology and Scientific Methods, IV., No. 25; Psychology as Science of Self. The same, V., Nos. I, 3, and 5 .

The following is an epitome of these important articles :

"This brief series of papers is written in the firm belief that the study of psychology is made more difficult and that the advance of psychology is checked, first, through the common failure to recognize explicitly the real subject-matter of the science and, secondly, through the under estimate of adequate description in psychology. Both tendencies reveal themselves in what I take to be a mischievous disregard for consistent, though provisional, definition and for adequate classifications." The series is, accordingly, introduced by a defense of definition and classification as a basis for teaching psychology and as an aid to psychological investigation. Some definition and classification there must be, since the facts are too many for the span of attention to cover individually. Again, though definition and classification may be premature and too rigid or may be merely verbal, these dangers do not lessen the value or necessity of making the attempt. Thus the problem of the papers is 'to define the basal fact of psychology and to outline the essential divisions of psychology.'

1. Psychology as a science of the idea: whose idea?

Of late years students of metaphysics have made various efforts ' to eject the term consciousness from our vocabulary,' but for the psychologist consciousness, as the opposite of the physical, must be accepted as a primary fact. "But even among psychologists who agree to define psychology as 'science of consciousness,' or 'science of mental life,' there is disagreement in regard to the further limitation of the conception." In fact there are three conceptions: (I) Psychology is the science of the mental state, or idea; (2) the science of the mental function; and (3) the science of the conscious self.

The last alone gives an adequate conception of the conscious life; and a critical examination of the two former conceptions will show that they implicitly imply this. Could, however, an explicit adoption of this view be had, it would clarify the treatment of psychology and 